\title{
Assessment of quality of life in adult patients with GH deficiency: KIMS contribution to clinical practice and pharmacoeconomic evaluations
}

\author{
Maria Koltowska-Häggström, Anders F Mattsson and Stephen M Shalet ${ }^{1}$ \\ KIMS Medical Outcomes, Pfizer Health AB, Endocrine Care, SE-190 91 Sollentuna, Sweden and ${ }^{1}$ Department of Endocrinology, Christie Hospital NHS \\ Trust, Manchester, M2O 4BX UK
}

(Correspondence should be addressed to M Koltowska-Häggström; Email: maria.koltowska-haggstrom@pfizer.com)

\begin{abstract}
Quality of life (QoL) has emerged as an important construct that has found numerous applications across healthcare-related fields, ranging from research and clinical evaluation of treatment effects to pharmacoeconomic evaluations and global healthcare policy. Impairment of QoL is one of the key clinical characteristics in adult GHD and has been extensively studied in the Pfizer International Metabolic Database (KIMS). We provide summarized evidence on GH treatment effects for both clinical and health economic applications based on the KIMS data. The primary focus is on those aspects of QoL research that cannot be investigated in the traditional clinical trial setting, such as specific patient subgroups, cross-country comparisons and long-term follow-up. First, the impact of age, gender, disease onset, primary aetiology, extent of hypopituitarism, previous radiotherapy and obesity on QoL before and during long-term GH replacement is discussed. Secondly, the studies on QoL in relation to country-specific normative values are reviewed. Finally, health economic data derived from KIMS including both burden of disease and utility assessment are evaluated. We conclude that the wide spectrum of analyses performed on the KIMS data allows for practical application of the results not only to research and clinical practice but also to health policy and global medical decision making.
\end{abstract}

European Journal of Endocrinology 161 S51-S64

\section{Introduction}

Quality of life (QoL) has emerged as an important construct that has found numerous applications across healthcare-related fields, ranging from research and clinical evaluation of treatment effects to pharmacoeconomic evaluations and global healthcare policy. Each of these applications imposes different requirements on the QoL measurement. For clinical applications, specific changes within a certain disease in patient populations (in clinical trials) and in individual patients (in daily clinical practice) (1) should be captured. On the other hand, pharmacoeconomic evaluation often requires that health status is expressed as a single summary score (a health status index), which is capable of identifying and quantifying differences between diseases as well as aggregate changes in patients' health status over time (2).

Impairment of QoL in hypopituitary adult patients not receiving $\mathrm{GH}$ replacement therapy has been evident for a long time (3). The most consistently observed complaints in untreated adult patients with $\mathrm{GH}$

This paper forms part of a special issue on $\mathrm{KIMS}^{\circledR}$ and ACROSTUDY $^{\mathrm{TM}}$. Pfizer Inc. has supported the publication of this special issue. deficiency (GHD) are related to energy levels, vitality, mental fatigue, emotional reactions, social isolation and anxiety (4-8). Additionally, reduced self-confidence, disturbed sex life (6), decreased physical mobility (4), dissatisfaction with body image (9), poor memory (10), reduced cognitive function and decreased mood (11), as well as attention deficits (12) have also been reported. A higher incidence of mental disorders, more pronouncedly expressed mental distress and relatively frequent cognitive dysfunctions complete this picture (13). The majority of these findings originate from early studies that were performed in relatively small patient cohorts followed for a limited period.

The benefits of GH replacement therapy, as assessed by randomized clinical trials, remain controversial $(14,15)$. The largest clinical trials that reported improvement in QoL in patients who received GH were conducted by Mårdh et al. $(n=233)$ (16), Attanasio et al. $(n=173)(17)$, Verhelst et al. $(n=148)(18)$, Chihara et al. $(n=73)$ (19), Deijen et al. $(n=48)(20)$, Carroll et al. $(n=42)(21)$, Burman et al. $(n=36)(22)$ and Wallymahmed et al. $(n=32)(7)$. In almost all of these studies, the benefits of GH were revealed by some, but not all instruments employed and/or were attributed to certain, but not all, dimensions measured; 
finally, they seemed to be heavily dependent on the degree of the initial impairment and were partly related to placebo effect. On the other hand, in the studies by Cuneo et al. $(n=166)$ (23), Beshyah et al. $(n=40)(24)$, Baum et al. $(n=40)(25)$ and Sathiavageeswaran et al. $(n=34)$ (26) no change in QoL in the treated patients was found.

Despite the fact that double-blind, randomized and placebo-controlled clinical trials are a gold standard in medical research, there are other clinical study settings that have been used to investigate $\mathrm{GH}$ treatment effects such as open treatment studies, withdrawal studies and surveillance studies (based on large observational research databases). In the latter category, HypoCCS (sponsored by Eli Lilly \& Co.) (27) and KIMS (Pfizer International Metabolic Database) have contributed most. The principle of such surveillance studies is to collect data on certain variables, accepting measurements recorded by individual investigators (28), with no restrictions regarding the number of patients enrolled or the duration of follow-up. They aim to collect information as it is recorded by the clinician, from any patient, with a given condition that they meet the criteria for the study. In other words, the rule is not to interfere with routine clinical practice. Not surprisingly, a large number of patients and corresponding extensive, longitudinal, long-term observations, as well as documentation of everyday clinical practice based in 'real life' are the characteristics of these kinds of studies. These properties provide the opportunity to detect rare adverse events and unexpected treatment responses, and also allows therapy to be monitored in GH-deficient patients as they appear in daily clinical practice. In addition, they also give new insights into atypical or very specific patient subgroups that otherwise would be very difficult to investigate in a traditional clinical trial.

The aim of this article is to provide summarized evidence on $\mathrm{GH}$ treatment effects for both clinical and health economic applications by reviewing QoL research in the KIMS database. The primary focus is on those aspects of QoL research that cannot be investigated in the traditional clinical trial setting, such as specific patient subgroups, cross-country comparisons and long-term follow-up.

\section{KIMS database}

KIMS, an international pharmacoepidemiological survey (29), was launched in 1994 at the request of endocrinologists and healthcare decision makers to monitor the outcomes and safety of long-term GH replacement therapy (Genotropin) in hypopituitary adults with GHD being treated in a conventional clinical setting. The study to date contains data on more than 14000 patients from 31 countries followed for $\sim 60000$ patient-years. The other aims of KIMS are to improve understanding of the consequences of GHD in adult hypopituitarism and to contribute to optimization of $\mathrm{GH}$ replacement.

To enter KIMS, one condition is that each centre obtains approval from its local ethics committee and that patients give informed consent, either verbally or in writing, depending on local legal requirements. Additionally, enrolment of participants follows good clinical practice guidelines.

KIMS is run according to the survey guidelines, the standardized guidance to all personnel involved in the clinics and at Pfizer (both nationally and globally). Data are collected electronically or through case report forms or questionnaires completed by the investigators or patients respectively and monitored at both national and central levels (in the Stockholm centralized database).

According to the 'By-laws of KIGS and KIMS', patient data belong to the participating investigators, and the database is scientifically governed at different levels (national and global) by advisory boards, which consist of representatives of the KIMS investigators. Pfizer owns the operating systems and provides financial support (29).

\section{QoL and other patient-reported outcomes: instruments used in the KIMS database}

To monitor QoL in patients followed in the KIMS database, two main questionnaires - QoL-Assessment of GHD in Adults (QoL-AGHDA) (30) and Psychological General Well-Being (PGWB) (31) - are routinely used. In the past, Nottingham Health Profile (NHP) (32) was applied as well. For the studies on the QoL-AGHDA, adaptation for health economic evaluations EQ-5D (33) was additionally employed. The patient's situation is recorded by the KIMS Patient Life Situation Form (KIMS PLSF) (34).

\section{QoL-AGHDA}

QoL-AGHDA is a disease-specific, need-based measure (35), which was developed based on in-depth interviews with adult patients with GHD $(n=35 ; 14$ men; age range 20-59 years) attending the Christie Hospital in Manchester, UK.

Almost all patients were dissatisfied with their body image and complained of lack of energy (94 and 91\% respectively), $83 \%$ had problems with memory and concentration, $71 \%$ described themselves as being short-tempered and easily irritated, 66\% suffered from lack of strength and stamina, 63\% experienced reduced physical and mental drive and $57 \%$ had difficulties coping with stressful situations and avoided external stimulation (9). 
The measure is constructed of 25 items that evoke yes/no answers, acknowledging or denying certain problems. The QoL-AGHDA score is computed by quantifying a number of recognized problems, i.e. each 'yes' answer is assigned a score of 1 , and therefore a high numerical QoL-AGHDA score denotes poor QoL. It is recommended that incomplete questionnaires should be excluded from the analysis. It has been shown to have good reliability, reproducibility, internal consistency and construct validity across a range of languages (30).

The population normative data for the QoL-AGHDA are available for the following countries: England and Wales (36-38), Spain (39), Sweden $(37,40,41)$ and The Netherlands (37). The data for Belgium, France and Germany are in press.

\section{Psychological General Well-Being}

The PGWB was produced as an index that was thought to measure self-representation of intrapersonal emotional states to reflect a sense of subjective wellbeing or distress (31). It contains six states (dimensions) - namely anxiety, depressed mood, positive well-being, self-control, general health and vitality - with three to five items assessed for each dimension. The items are rated on a scale of $0-5$ for their intensity or frequency; 0 being the worst score and 5 being the best score. The sum of the item scores constitutes an overall PGWB index score, which ranges from 0 to 110 . A high score denotes good QoL. McKenna \& Hunt adapted the PGWB for use in the UK and Europe, and this modified version is often referred to as the General Well-Being Index (GWBI or AGWBI) (42).

\section{KIMS PLSF}

KIMS PLSF (43) is a patient-reported outcomes (PRO) questionnaire that records information about the patient's personal situation, societal functioning, use of social care and healthcare resources as well as need for assistance with daily activities. In addition, KIMS PLSF contains two visual analogue scales (VAS) for assessment of the level of and satisfaction with physical activity, and 5-step Likert scale examining subjective satisfaction with treatment.

\section{EQ-5D}

The EQ-5D, designed as a generic instrument to measure health, independent of diagnosis or disease severity (33), defines five dimensions of health: mobility, self-care, usual activities, pain or discomfort and anxiety or depression. Each dimension is categorized into three levels of burden: i) no problem, ii) a moderate problem and iii) an extreme problem. The combination of three categories for the five dimensions generates 243 health states with death and unconsciousness, in addition. The respondents first indicate the level of burden that is best applicable and then record their perception of their general health state on the feeling thermometer (VAS).

\section{Nottingham Health Profile}

NHP is a generic instrument that measures emotional, social and physical distress. It comprises 38 dichotomous items (yes/no answers) organized in six dimensions: sleep, pain, emotional reactions, social isolation, physical mobility and energy level. In earlier versions, NHP also contained seven statements about the extent to which such distress impacts daily activities. Although in essence NHP provides a profile of distress in the six dimensions, it is possible to compute a single score based on weighted or unweighted profile scores (32).

\section{QoL in adult GHD: clinical approach}

\section{Impact of demographic and clinical characteristics}

Gender and age As early as in 1999, the first KIMS studies showed that before GH treatment women demonstrate a higher degree of QoL impairment than men (mean (95\% CI) QoL-AGHDA score 10.2 (9.1$11.3)$ vs $6.1(6.0-8.2)$ respectively) (44), and that the improvement after 12 months of treatment is greater in women (mean -4.8 points in QoL-AGHDA score) than in men (-2.8) (45). Similar results were consistently reported from subsequent studies in the total KIMS population (43) as well as in different cohorts such as patients aged below and above 65 years (46), originating from a single country $(34,36,37,47$, 48 ), and those who developed GHD following treatment for acromegaly and Cushing's disease (49), childhoodonset (CO) craniopharyngioma (50), adult-onset (AO) non-functioning pituitary adenoma (NFPA) (51) and CO-brain tumours (52). The only exceptions are patients with AO-craniopharyngioma (50) and with CO-GHD due to causes other than craniopharyngioma and brain tumours (52) in whom a gender difference in QoL was not observed. Some studies showed similar rates of change in QoL during the treatment in both genders $(34,43)$.

The results of the studies analysing the impact of age on QoL before commencing GH are inconsistent. Some of them indicate no difference between the age groups $(36,46,53)$, others suggest better QoL in younger patients $(38,48)$. Nevertheless, the first observation of Bengtsson et al. (45) that age has no impact on beneficial effects of $\mathrm{GH}$ therapy was confirmed by Monson et al. in the studies $(46,53)$ comparing patients with AO-GHD aged below and above 65 years as well as in the recent analysis of response to treatment based on utilities (38). 
Disease onset Some of the results from the KIMS database are in agreement with previously published papers (17) showing that patients with AO disease suffer from deeper psychological distress and experience poorer QoL than those who acquired disease during childhood $(36,38,50,54)$. Others, mainly the early studies were unable to detect any difference between CO and $\mathrm{AO}$ patients, an observation that could be related to the low number of patients with CO disease $(43,44)$. Interestingly, the initial lesser degree of QoL impairment in patients with CO-GHD does not diminish their response to GH treatment and as shown by Abs et al. (54) and later on by Höybye et al. (52) all patients with CO-GHD, regardless of primary cause, benefited in QoL from treatment.

Extent of hypopituitarism: other pituitary hormone deficits and IGF1 It has been shown that both isolated GHD and multiple pituitary hormone deficits (MPHD) affect QoL to a similar degree $(43,54)$, and comparable improvements during the $\mathrm{GH}$ replacement occur in both groups. Abs et al. (54) reported the following decreases after 12 months of $\mathrm{GH}$ in the mean (s.E.M.) QoL-AGHDA scores: in AO, $-5.3(0.9)$ in isolated GHD and - $3.8(0.2)$ in MPHD and in CO, $-3.2(1.0)$ and $-3.5(0.4)$ in isolated GHD and MPHD respectively. None of the comparisons reached statistical significance.

Similarly, positive responses to $\mathrm{GH}$ in QoL were observed, while comparing eugonadal men with those who had AO hypogonadism (55).

The recent study of Moock et al. (48) failed to detect any correlation between the serum concentration of insulin-like growth factor-I (IGF1) and QoL-AGHDA scores. Nevertheless, when patients were categorized by IGF1 SDS, those with IGF1 SDS between -2 and 2 have lower mean QoL-AGHDA scores (after 12 months of
GH treatment: 5.1 in men and 5.2 in women) than those with IGF1 SDS below -2 (7.0 and 6.9 in men and women respectively) or above 2 (6.3 and 6.1 men and women respectively).

Previous radiotherapy Maiter et al. (56) studied clinical characteristics and 1- and 2-year responses to $\mathrm{GH}$ treatment in GH-deficient patients who were previously irradiated for pituitary adenoma or craniopharyngioma in comparison with those who were not. Although before GH treatment irradiated patients suffered from greater impairment of QoL (mean (s.D.) QoL-AGHDA score 10.4 (5.9)) than patients without irradiation (mean (s.D.) QoL-AGHDA score 9.3 (6.5); $(P<0.02))$, there was no difference in the rate of improvement after 1 and 2 years of treatment.

Primary aetiology The overview of QoL in untreated GHD depending on primary aetiology is shown in Fig. 1.

Acromegaly and Cushing's disease. Women with GHD caused by treatment of acromegaly or Cushing's disease had poorer QoL before treatment than those patients who acquired deficiency due to other aetiologies (mean QoL-AGHDA score: 14.7; 13.4 and 10.0 respectively) (49). Furthermore, analysis of response to GH after 6 months of treatment showed improvement only in patients with other aetiologies, which most likely reflected the low number of patients with acromegaly and Cushing's disease.

Craniopharyngioma. There have been two studies on craniopharyngioma treatment-related GHD in adult patients based on the KIMS database: the first compared clinical features of patients with CO-craniopharyngioma versus those with AO-craniopharyngioma, before they started GH replacement as adults (50) and the second addressed AO-craniopharyngioma in comparison with

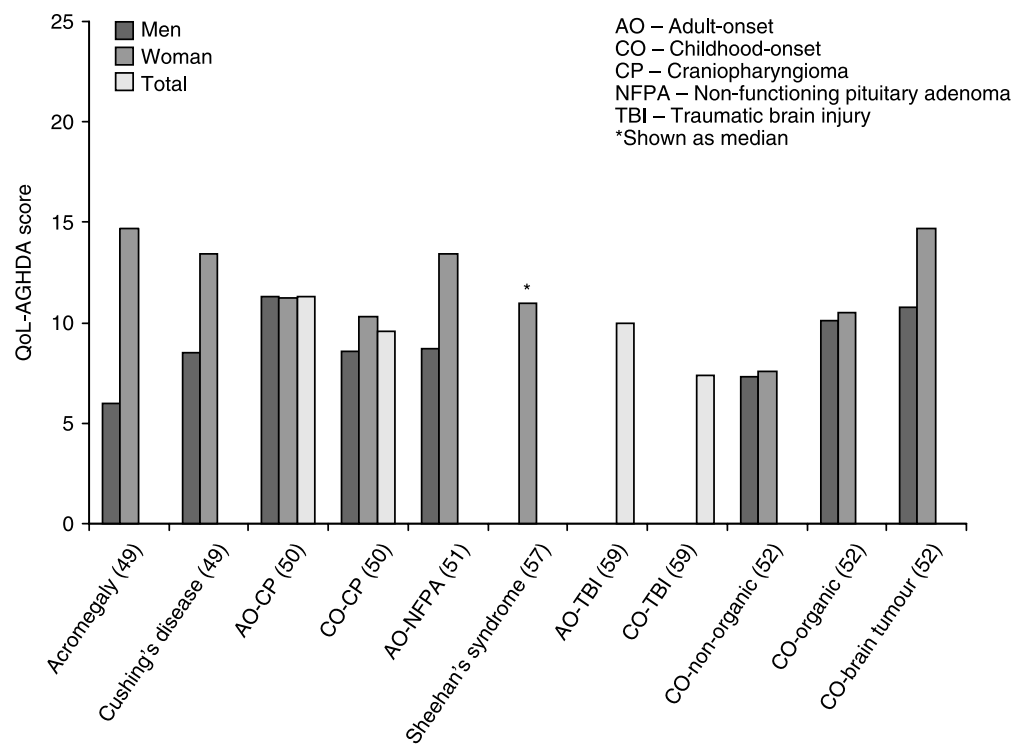

Figure 1 Pretreatment QoL-AGHDA scores in KIMS patients with GH deficiency by primary aetiology. Data shown are means, reference number is given in brackets.

www.eje-online.org 
AO-NFPA (51). Both papers showed impaired QoL before patients started GH therapy. The former study confirmed previous observations (17) that patients with craniopharyngioma who acquired disease in childhood also reported better QoL than those who developed the disease as adults (9.6 S.D. 6.83 vs 11.3 S.D. 6.93 respectively $P<0.05$ ). The latter study observed gender-specific differences in QoL, namely male patients with craniopharyngioma experienced worse QoL (11.6 s.D. 7.5) than those with NFPA (8.7 S.D. $6.9 P<0.01$ ), while the opposite was true for women (10.6 S.D. 6.3 in craniopharyngioma versus 13.4 s.D. 7.3 in NFPA $P<0.01$ ). A significant improvement after 2 years of $\mathrm{GH}$ treatment was observed in all groups of patients (51).

Non-functioning pituitary adenoma. Patients with GHD caused by NFPA are often used in the KIMS analyses as comparators while studying GHD due to other aetiologies. Thus, in the majority of papers, they are matched for gender and age to reflect characteristics of the main study arms, and therefore the results may not truly apply to the typical NFPA patients. For example, Keleştimur et al. reported median pretreatment QoLAGHDA score of 8 in young women with NFPA (57), and similarly the results described above originate from the NFPA cohort, matched for age and gender with craniopharyngioma patients.

The only analysis that was carried out in a stand-alone cohort of GH-deficient patients due to treatment of NFPA, studied patients who were aged below $(n=273)$ and above $(n=130) 60$ years. None of the patients received GH treatment before entry into KIMS, all had three or four additional, pituitary hormone deficits and did not receive radiotherapy during the treatment of their adenoma. Patients were followed for 6 years and the exact patient numbers at each time point are displayed in Fig. 2. In the younger group, the mean QoL-AGHDA score of 9.6 (95\% CI: 8.81-10.46) decreased to 4.7 (95\% CI:

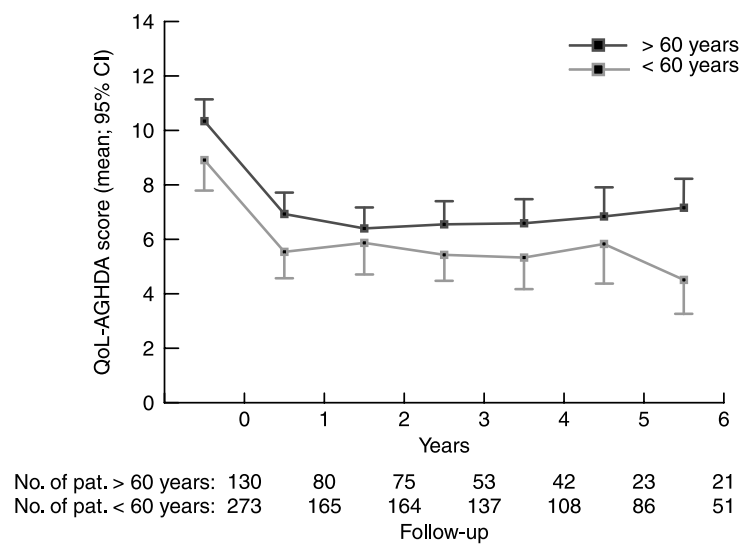

Figure 2 Comparison of QoL-AGHDA scores during 6 years of $\mathrm{GH}$ treatment in $\mathrm{GH}$-deficient patients with non-functioning pituitary adenoma, aged below and above 60 years. For a clearer picture, only the lower or upper half of the symmetric confidence intervals are depicted.
3.00-6.45) $(P<0.0001)$ after 6 years of GH replacement. Improvement was also observed in older patients: pretreatment mean QoL-AGHDA score of 8.1 (95\% CI: 6.96-9.26) was reduced to 3.1 (95\% CI: 1.08-5.11; $P<0.0001$; Fig. 2). Younger patients reported worse QoL (higher QoL-AGHDA scores) than older patients at GH start $(P<0.05)$ and after 6 years of treatment.

Sheehan's syndrome. As reflected by QoL-AGHDA scores, women with Sheehan's syndrome felt psychologically worse than those with NFPA (median 11 vs 8 respectively $P<0.001$ ) but responded to $\mathrm{GH}$ treatment equally well (57).

Traumatic brain injury. The first KIMS study on patients who suffered from traumatic brain injury (TBI) as adults evaluated response to $\mathrm{GH}$ in a relatively small number of patients $(n=15)$ in comparison to age- and gender-matched NFPA group $(n=125)$ and detected significant change in QoL-AGHDA score after 1 year of GH only in the NFPA group (58). In the second study, Kreitschmann-Andermahr et al. reported a similar degree of QoL impairment in German patients with TBI and NFPA (mean QoL-AGHDA score 8.8, s.D. 6.3 and 8.7 , s.D. 6.6 respectively NS) and additionally significant improvement after 1 year of $\mathrm{GH}$ replacement in the TBI group (59).

QoL depending on obesity parameters An interesting approach was adopted by Abrams et al. (60) who in their study analysed QoL depending on body mass index (BMI), waist circumference and fat mass. The study was twofold. First, the authors showed that pretreatment QoL was adversely affected in all groups, but the impairment was greater in obese patients (mean QoLAGHDA score 12.1, s.D. 7.2) compared with those with normal BMI and overweight (9.8, s.D. 7.1 and 9.5, s.D. 7.0; $P<0.001)$. There was no difference between patients with normal BMI and overweight. Similar observations applied to patients with normal and abnormal waist circumference (9.8, S.D. 7.2 vs 11.2 , S.D. 7.1 respectively $P<0.001)$. In a further analysis, they evaluated changes in QoL-AGHDA scores after 1 year of $\mathrm{GH}$ in patients categorized by a change in the same obesity parameters; i.e. decreased, no change and increased BMI, waist circumference and fat mass. Surprisingly, all groups benefited from GH treatment $(P<0.001)$; however, the most pronounced improvements were observed in those patients who lost weight.

\section{Evaluation of QoL in relation to the country- specific general population values}

Despite stringent methods applied to the translation and cultural validation of different language versions of instruments, there is substantial inter-country variation in QoL, which is particularly evident in measuring those aspects of QoL that are more complex and depend on 
mentality, culture and perception of well-being $(61,62)$. Such variation was also observed in measuring QoL in patients with GHD (63).

General population mean QoL-AGHDA scores (adjusted for gender and modelled at 50 years of age) differ between the countries with the highest score obtained in the sample from England and Wales (6.7), followed by Spain and The Netherlands (5.0 in both countries) and Sweden (3.9) (37). The KIMS studies assessed QoL deficit in patients in relation to the country-specific general population values and detected cross-country differences in pretreatment results, but a similar pattern of response to GH. Before the start of $\mathrm{GH}$ treatment, the greatest difference between mean QoLAGHDA scores in the general population and KIMS patients was found for England and Wales (-9.0, 95\% CI: -9.63 and -8.47$)$, followed by the Spanish $(-7.1$, 95\% CI: -7.89 and -6.36$)$, Dutch $(-5.0$, 95\% CI: -5.75 and -4.23$)$ and Swedish $(-4.4,95 \%$ CI: -4.92 and -3.89$)$ patients. This observation most likely reflects the variation in criteria for GH treatment adopted in the studied countries. The analysis of the effects of $\mathrm{GH}$ treatment showed the greatest improvement during the first year of therapy, followed by less rapid decrease in the mean QoL-AGHDA score moving inexorably towards the country-specific normative values. Similar patterns of response were found in other subsets of patients, e.g. men, women, $\mathrm{CO}$ and $\mathrm{AO}$, with NFPA and craniopharyngioma (37).

Comparison between patients aged below and above 60 years Similar type of analysis was performed to compare QoL in GH-deficient patients aged below and above 60 years from England and Wales (follow-up 6 years), The Netherlands (follow-up 5 years) and Sweden (follow-up 6 years). The total numbers of patients before GH start were: England and Wales, $<60$ years, $n=737$ (46\% men) and $\geq 60$ years, $n=174$ (55\% men); The Netherlands, $<60$ years, $n=221$ (47\% men) and $\geq 60$ years, $n=55(65 \%$ men $)$ and in the Swedish cohort, $n=378$ (50\% men) and $n=146$ (53\% men). The exact numbers of patients per year of follow-up as well as numbers of individuals in general population samples are presented in Fig. 3. The mean IGF1 SDS before GH therapy and the mean starting GH doses per country are displayed in Table 1. Overall, adjusted for gender, QoL in patients in both age groups and in each country was significantly impaired in comparison with their peers from the general population with the greatest extent of deterioration observed in the English and Welsh patients (data not shown). Additionally, in each country, older patients experienced a lower degree of impairment in QoL than younger patients. Overall, the beneficial effects of GH treatment moving the patients' QoL scores towards the country- and age-specific general population values were observed in each group, but there was a remarkable variation in the extent of improvement. The Dutch and Swedish patients in both age groups approached the

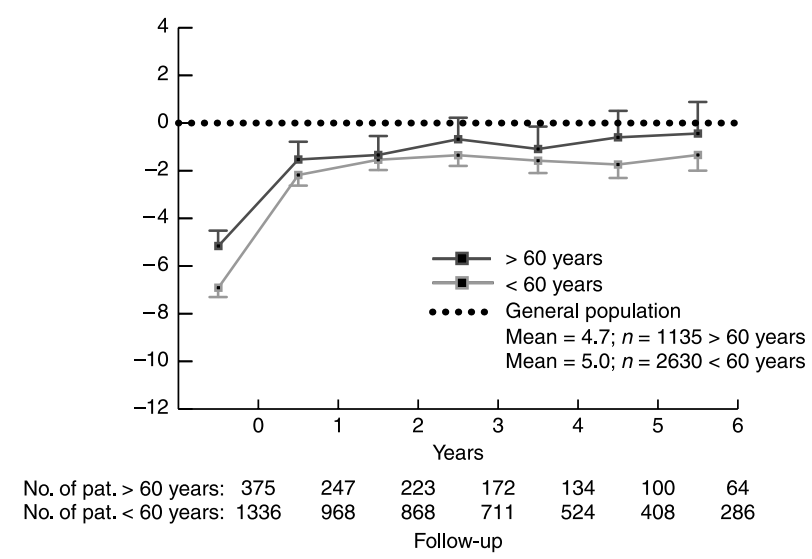

Figure 3 Response in QoL (as measured by the QoL-AGHDA in relation to general population values) during long-term $\mathrm{GH}$ treatment in $\mathrm{GH}$-deficient patients aged below and above 60 years. Pooled data from England and Wales, The Netherlands and Sweden. The dotted line depicts general population level. For a clearer picture, only the lower or upper half of the symmetric confidence intervals are depicted.

level reported in respective general population samples earlier than patients in England and Wales. Furthermore, older patients in the former countries responded to GH treatment in QoL better than younger patients (data not shown). The analysis performed on the pooled data yielded the same results (Fig. 3). In conclusion, the pattern of response to $\mathrm{GH}$ was identical in younger and older patients as previously described (37) with the most dramatic improvement during the first year of $\mathrm{GH}$, which thereafter continued in a less rapid manner drifting gradually towards the general population values.

Comparison between younger and older patients with CO-GHD The lesser extent of QoL deterioration in patients with CO-GHD compared with AO-GHD was previously reported (17), but there is no information on how QoL in patients with CO disease relates to age-, gender- and country-matched general population values and no difference between younger and older patients. Therefore, the same methodology as described above was applied to compare patients with CO-GHD aged 18-25 years with those aged 26-50 years. Both general population and patient data originated from four countries (England and Wales, The Netherlands, Spain and Sweden). All patients were off GH for at least 6 months prior to the entry into KIMS. Before GH, patients in both groups demonstrated deficit in QoLAGHDA scores compared with the general population values. The deficit was smaller in younger patients $(-4.1,95 \%$ CI: -4.97 to -3.15$)$ than in older patients $(-5.9,95 \% \mathrm{CI}:-6.64$ to -5.24$)$. The absolute mean values of QoL-AGHDA scores were as follows: in the younger group, general population $(n=464) 5.4(95 \%$ CI: 4.91-5.98) and in patients $(n=245) 9.5$ (95\% CI: 8.81-10.20), and in the older 
Table 1 The mean insulin-like growth factor-I (IGF1) SDS and GH dose per age and country. Data shown as mean (S.D).

\begin{tabular}{|c|c|c|c|c|c|c|}
\hline & \multicolumn{2}{|c|}{ England and Wales } & \multicolumn{2}{|c|}{ The Netherlands } & \multicolumn{2}{|c|}{ Sweden } \\
\hline & $<60$ years & $\geq 60$ years & $<60$ years & $\geq 60$ years & $<60$ years & $\geq 60$ years \\
\hline IGF1 SDS at baseline & $-1.5(1.64)$ & $-1.3(1.19)$ & $-2.3(1.74)$ & $-2.1(1.75)$ & $-2.1(1.79)$ & $-1.8(1.41)$ \\
\hline IGF1 SDS at 1 year & $0.5(1.43)$ & $0.8(1.40)$ & $0.3(1.56)$ & $0.7(1.36)$ & $0.1(1.42)$ & $0.5(1.31)$ \\
\hline $\mathrm{GH}$ dose at baseline ( $\mathrm{mg} /$ day) & $0.28(0.12)$ & $0.24(0.12)$ & $0.21(0.14)$ & $0.20(0.13)$ & $0.13(0.14)$ & $0.11(0.08)$ \\
\hline $\mathrm{GH}$ dose at 1 year (mg/day) & $0.38(0.20)$ & $0.31(0.14)$ & $0.40(0.21)$ & $0.27(0.14)$ & $0.34(0.18)$ & $0.26(0.13)$ \\
\hline
\end{tabular}

group: $n=1988,5.0$ (95\% CI: 4.75-5.24) and $n=263$, 10.9 (95\% CI: $10.29-11.58)$ respectively. The response to GH treatment was evaluated during 6 years of followup and the results showed beneficial effects consistent with those observed in the previous studies (Fig. 4); however, younger patients reached the QoL levels of the general population earlier than older patients. It can be concluded that patients with CO-GHD regardless of their age demonstrate considerable deterioration in QoL before they restart $\mathrm{GH}$ and benefit from $\mathrm{GH}$ therapy.

QoL dimensions affected in GHD The randomized clinical trials revealed that GHD mostly affects energy levels, emotional reactions, cognition function and social functioning. Problems in these dimensions are reflected in the QoL-AGHDA items, which for the subset of studies were categorized into: problems with socialising, tenseness, self-confidence, tiredness, and memory and concentration. The scores for each dimension were standardized as percentage of items within a dimension that a respondent expressed problems with. The comparisons between levels of problems in general population samples and patients in the age-, genderand country-matched manner were performed.

The general analyses of pretreatment scores showed significant impairment in patients on all QoL dimensions compared with respective population data. In all countries, problems with memory and tiredness

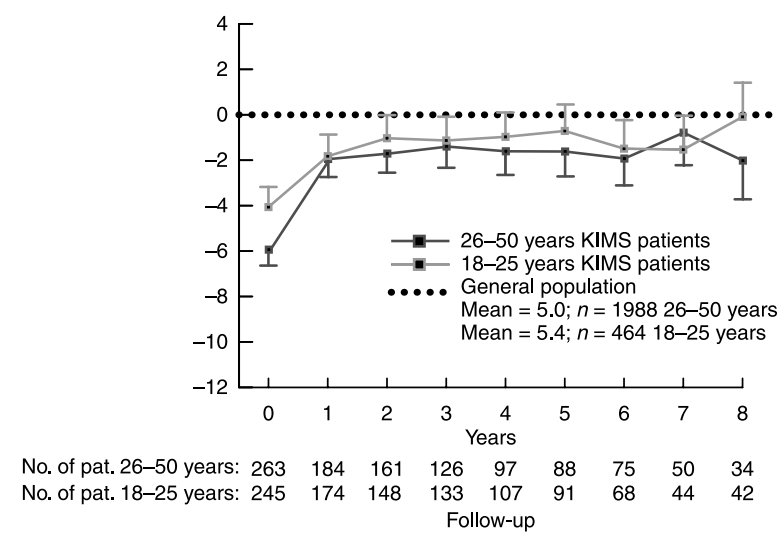

Figure 4 Response in QoL (as measured by the QoL-AGHDA in relation to general population values) during long-term $\mathrm{GH}$ treatment in patients with childhood-onset GH deficiency by age groups. Dotted line depicts general population level. For a clearer picture, only the lower or upper half of the symmetric confidence intervals are depicted. considerably exceeded those reported in other dimensions, and despite significant improvement during treatment, these two dimensions remained adversely affected throughout the follow-up (between 2 and 7 years). The first dimension to reach the population levels was social isolation regardless of the country of origin, followed by tenseness and problems with selfconfidence (37).

To examine whether there is age-related specificity in the behaviour of QoL dimensions during long-term GH replacement (6 years), similar analysis was conducted in patients aged below and above 60 years. The data were available for 2630 individuals aged $<60$ years in the general populations from England and Wales, The Netherlands and Sweden together with patient data ( $n=1336$ before GH start) from corresponding countries. The older groups consisted of 1135 persons in the general population and 375 patients. The exact patient numbers per year of follow-up as well as response to treatment per dimension are presented in Fig. 5, and GH dose and IGF1 SDS in Table 1. In summary, older individuals in the general population reported more problems with memory and concentration and tiredness, but less problems with tenseness, socialising and self-confidence, than the younger people. Although, patients in both age groups reported deficit in QoL before $\mathrm{GH}$ treatment, on average older patients experienced fewer problems in all dimensions than younger patients. Overall, the most dramatic improvement in both patient groups occurred during the first year of GH therapy for all dimensions, which was sustained during the followup. Interestingly, older patients within 2-3 years of treatment reached the general population levels in all dimensions, whereas the younger patients after 2 years of treatment only normalized problems with socialising. In the latter group, only tenseness and self-confidence were indistinguishable from the general population by the end of follow-up, and memory and concentration as well as tiredness remained adversely affected, despite significant improvement during treatment.

The last group of KIMS patients studied for dimensional response in QoL were patients with CO-GHD divided into younger (18-25 years) and older groups (26-50 years). All reported significantly more problems (Table 2) in all dimensions compared with the general population, and surprisingly, the order of impairment was identical as identified in the studies described above. There was a slight tendency in older patients to report 
(a)

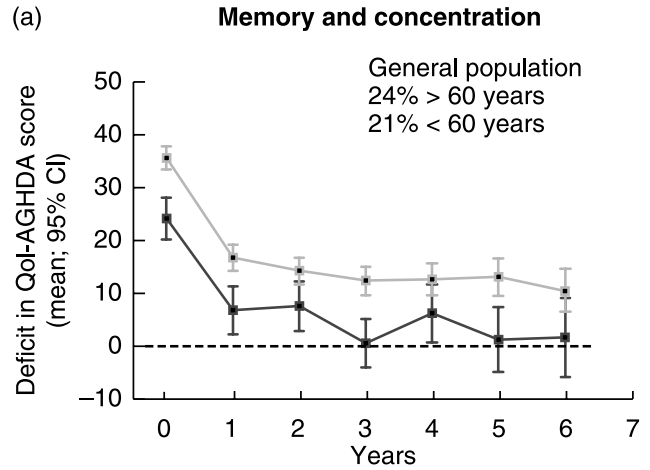

No. of pat. $>60$ years: $\begin{array}{lllllll}375 & 247 & 223 & 172 & 134 & 100 & 64\end{array}$ No. of pat. $<60$ years: $\begin{array}{lllllll}1336 & 968 & 868 & 711 & 524 & 408 & 286\end{array}$

Follow-up

(c)

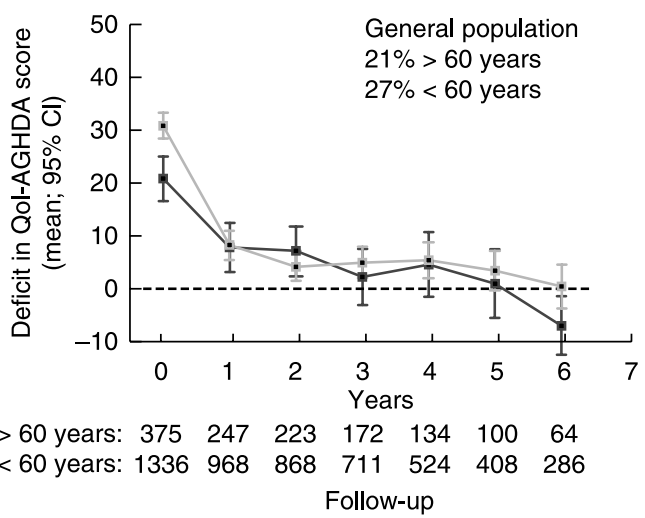
$\begin{array}{llllllll}\text { No. of pat. }>60 \text { years: } 375 & 247 & 223 & 172 & 134 & 100 & 64 \\ \text { No. of pat. < } 60 \text { years: } 1336 & 968 & 868 & 711 & 524 & 408 & 286\end{array}$ Follow-up (b)

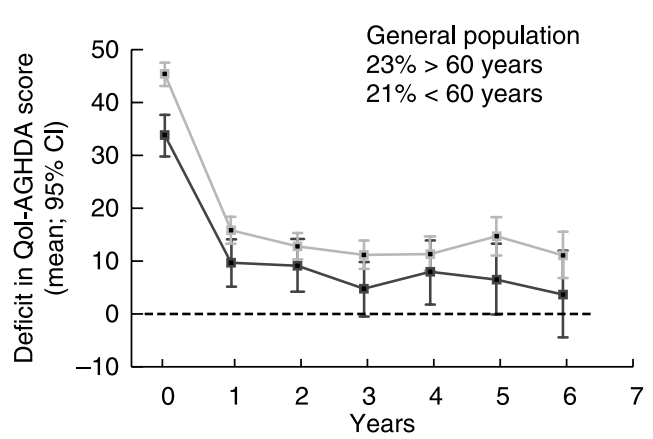

No. of pat. $>60$ years: $\begin{array}{lllllll}375 & 247 & 223 & 172 & 134 & 100 & 64\end{array}$

No. of pat. < 60 years: $\begin{array}{lllllll}1336 & 968 & 868 & 711 & 524 & 408 & 286\end{array}$

Follow-up

(d)

Socialising

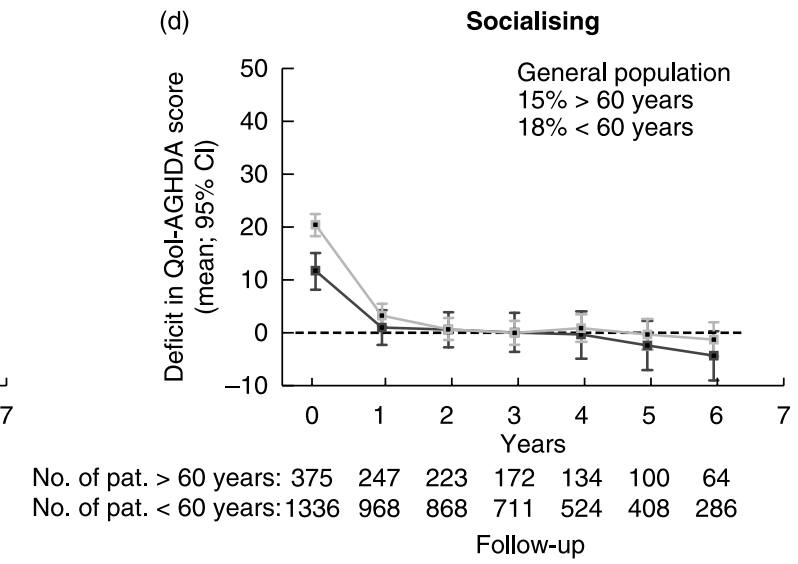

No. of pat. > 60 years: $\begin{array}{lllllll}375 & 247 & 223 & 172 & 134 & 100 & 64\end{array}$ No. of pat. $<60$ years:1336 $968 \quad 868 \quad 711 \quad 524 \quad 408 \quad 286$

(e)

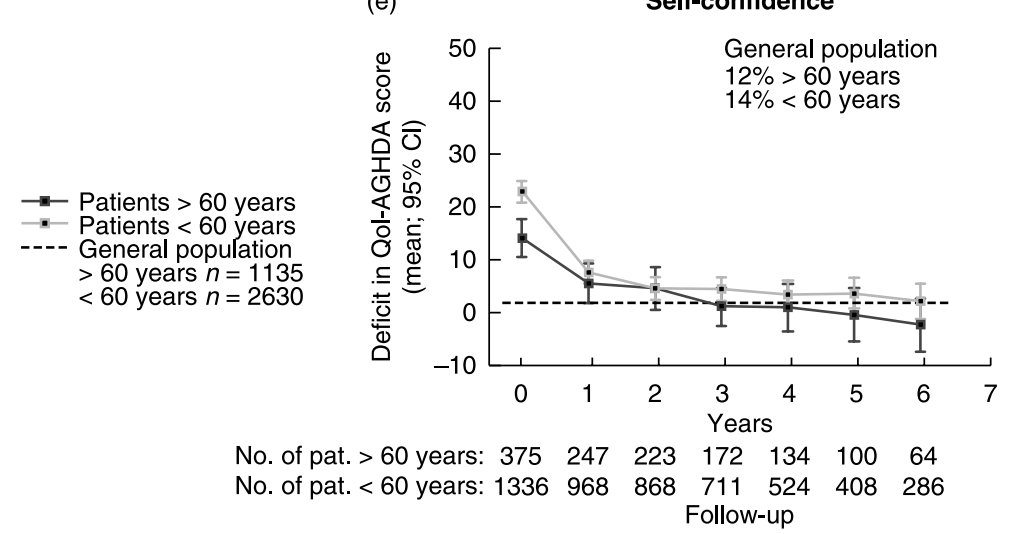

竎

Self-confidence

Figure 5 Response in QoL dimensions (as measured by the QoL-AGHDA in relation to general population values) during long-term GH treatment in GH-deficient patients aged below and above 60 years; (a) memory and concentration, (b) tiredness, (c) tenseness, (d) socialising and (e) self-confidence. The dotted line reflects the mean percentage of recognized problems (impairment) for each dimension in general population level (the absolute values per age group and dimension are displayed). The $y$-axis depicts the percentage of additional impairment in patients with GHD in relation to the general population values. Reaching the dotted line means getting closer to the general population values.

greater extent of problems than younger patients. In both age-groups, the patterns of response to $\mathrm{GH}$ mimicked those previously reported (Fig. 6).

The innovative finding of the KIMS studies on QoL dimensions is consistent sequence of dimensions ordered by a degree of impairment, i.e. memory and concentration and tiredness affected most, followed by self-confidence, tenseness and social isolation. Strikingly, improvement with GH treatment seems to occur in the reverse order with the dimension impaired to the least extent (problems with socialising), normalising first (Fig. 7). 
Table 2 Mean percent of increase in proportion of problems recognized by patients with childhood-onset GH deficiency by age in relation to general population.

\begin{tabular}{lcc}
\hline & $\mathbf{1 8 - 2 5}$ years (\%) & 26-50 years $(\%)$ \\
\hline Memory and & 24 & 28 \\
$\quad$ concentration & 28 & 32 \\
Tiredness & 19 & 28 \\
Tenseness & 15 & 19 \\
Socialising & 17 & 22 \\
Self-confidence & & \\
\hline
\end{tabular}

\section{Health economic evaluations}

\section{Healthcare utilization}

Both consumption of healthcare resources and patients' personal and societal functioning largely modify a burden of disease and are major contributors to societal healthcare costs. The first assessment of the burden of GHD was undertaken in a Belgian cohort of adults with untreated GHD $(n=129)$. The study showed reduced QoL (measured by SF-36) and a higher rate of unemployment due to health problems ( $11 \%$ of patients versus $4.8 \%$ of the Belgian population), accompanied by a higher annual number of sick leave days in those who were employed (twice as high as the population average). Healthcare utilization, expressed as an annual number of visits to general practitioners and specialists as well as hospitalization days, was also higher than in the general population. Overall, the estimated annual healthcare costs and costs of diminished productivity per hypopituitary patient approximately doubled the mean annual costs per person for the Belgian population (64).

The results of large Spanish longitudinal survey in untreated GH-deficient patients $(n=356)$ reflected a similar tendency (65). The detailed Swedish analysis of total societal costs of hypopituitarism when conventional hormonal replacement for all pituitary axes except for GH was administered, yielded concordant results (66).

One randomized clinical trial showed a decrease in the number of hospitalization days and sick leave days in patients who received an active drug (18).

The first KIMS report on the reduction in sick leave days, doctor visits, hospitalization days and need for assistance in daily activities during the first 12 months of GH replacement was based on the patient data pooled from several European countries (43). In order to eliminate the impact of different healthcare systems, two other studies in a single country environment were conducted. Furthermore, these studies evaluated GH effects after 2 (34) and 3 years (47) and attempted to identify the relation between changes in QoL and healthcare consumption. In the Swedish study, the number of doctor visits and hospitalization days was reduced after 3 years, whereas the number of sick leave days decreased after 2 years and returned towards baseline values after 3 years. There was no change in the proportion of patients who reported a need for assistance in daily activities. Level of and satisfaction with leisure physical activity increased and was correlated with improvement in QoL, but there was no relation between changes in QoL-AGHDA scores and consumption of healthcare resources. These findings were concordant with the results obtained in the German and Dutch cohorts during 2 years of GH treatment (34).

Two other studies examined employment status at the time of entry into KIMS in patients with GHD caused by treatment for craniopharyngioma, both $\mathrm{CO}$ and $\mathrm{AO}$. Out of 257 patients, $8.9 \%$ of $\mathrm{CO}$ and $3.8 \%$ of AO patients were unemployed but fewer CO patients $(15.8 \%)$ than AO (19.2\%) were on sickness benefit. The latter finding may be related to the higher employment rate in the AO patients (50). Similar employment rates were described in patients with AO-craniopharyngioma and AO-NFPA (51). The proportion of patients unable to work because of sickness or disability was equally high in both groups - between 17 and $18 \%$.

\section{QoL measurement for use in pharmacoeconomic evaluations}

Pharmacoeconomic evaluation, commonly used in medical decision making, requires that health status is expressed as a preference-based single summary score (a health status index), which is capable of identifying and quantifying differences across diseases as well as aggregate changes in health status over time (2). Quality-adjusted life year (QALY), a most frequently used health status index, combines information on the length of life (quantity) and the QoL, where the latter is measured by utilities on a scale that has values of 1 and 0 respectively for full health and death (67). The unit QALY is therefore defined as 1 year of life with full health (68). In the theoretical basis for QALY provided by Torrance, full health was defined as 'perfect functioning'. Utilities are an individual's preferences for a certain health state assigned under uncertainty (69). As condition- or disease-specific measures, e.g. the QoLAGHDA, are not preference-based they lack legitimacy for direct use in cost-utility analysis. Hence, there is a need for transformation to derive utilities to be able to compute QALY and thus to apply treatment results as measured in clinical practice to pharmacoeconomic evaluation.

The first attempt to derive utilities for changes in QoL during GH treatment was undertaken in the UK by NICE. Two-step mapping was performed. First, NHP scores were mapped on to the SF-6D, which generated NHP-based utilities, and these were subsequently mapped on to QoL-AGHDA scores (70). The results of this method should be viewed with caution as it incorporated indirect mapping between NHP and QoLAGHDA in different datasets, which may lead to inaccuracy. Furthermore, during the initial step, 
(a)

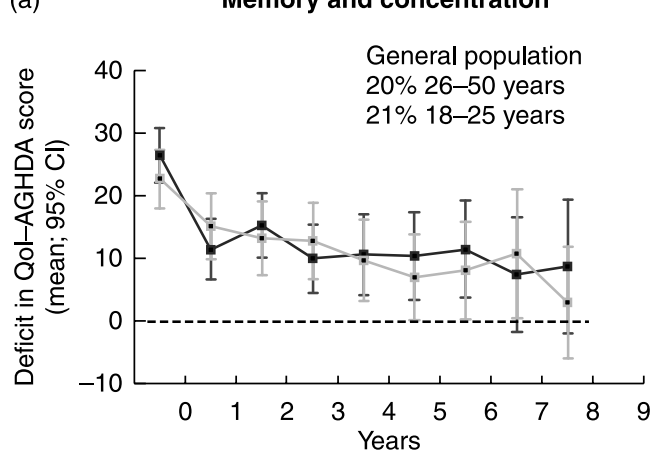

No. of pat. 26-50 years: $264186165127 \quad 101 \quad 90 \quad 75 \quad 50 \quad 34$ No. of pat. 18-25 years: $2461781481391089271 \quad 4542$

Follow-up

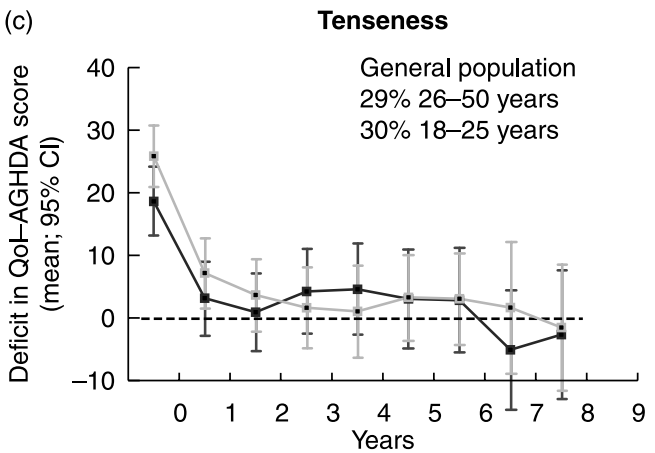

No. of pat. 26-50 years: $26418616512710190 \quad 75 \quad 50 \quad 34$ No. of pat. 18-25 years: $24617814813910892 \quad 71 \quad 45 \quad 42$ Follow-up (b) Tiredness

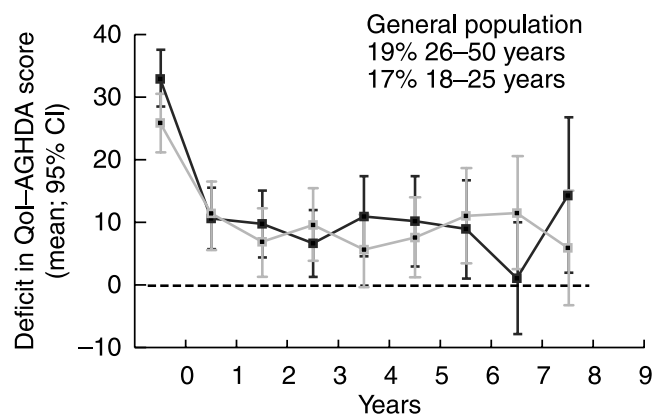

No. of pat. 26-50 years: $26418616512710190 \quad 75 \quad 50 \quad 34$ No. of pat. 18-25 years: $24617814813910892 \quad 71 \quad 4542$

Follow-up

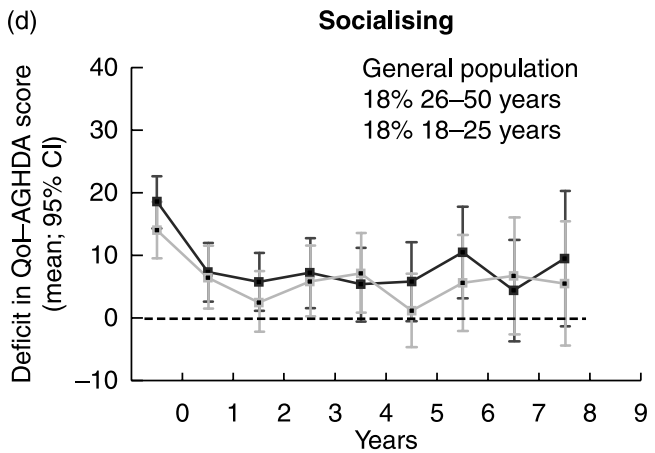

No. of pat. 26-50 years: $26418616512710190 \quad 75 \quad 50 \quad 34$ No. of pat. 18-25 years: $24617814813910892 \quad 71 \quad 45 \quad 42$ Follow-up

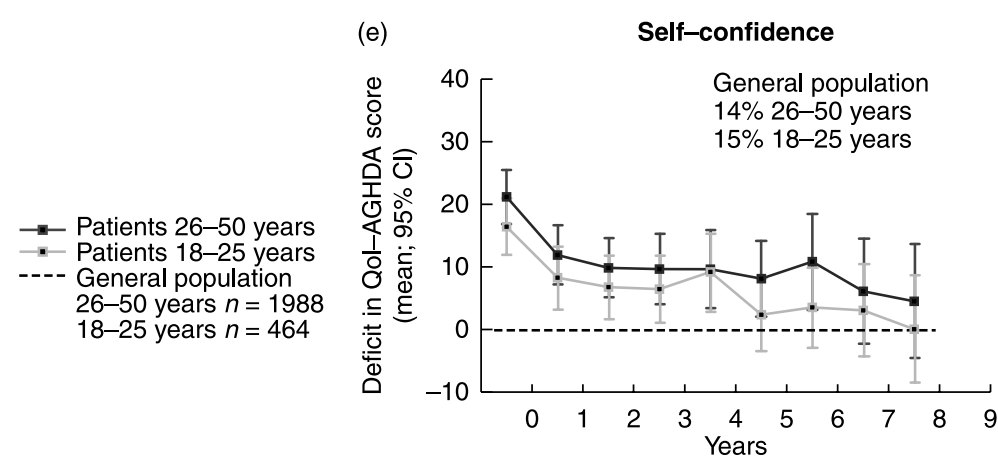

No. of pat. 26-50 years: $26418616512710190 \quad 75 \quad 50 \quad 34$ No. of pat. 18-25 years: $24617814813910892 \quad 71 \quad 45 \quad 42$

Follow-up

Figure 6 Response in QoL dimensions (as measured by the QoL-AGHDA in relation to general population values) during long-term GH treatment in patients with CO-GHD. (a) Memory and concentration, (b) tiredness, (c) tenseness, (d) socialising, (e) self-confidence. The dotted line reflects the mean percentage of recognized problems (impairment) for each dimension in general population level (the absolute values per age group and dimension are displayed). The $y$-axis depicts the percentage of additional impairment in patients with GHD in relation to the general population values. Reaching the dotted line means getting closer to the general population values.

NHP-based utilities were estimated for general practice patients, but not for the general population (as requested by health economists).

Within the scope of the KIMS database, models for

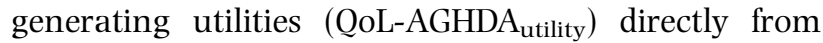
QoL-AGHDA were developed. They were based on EQ5D and QoL-AGHDA data collected in separate surveys in the general population samples in England and Wales and Sweden $(36,41)$. Subsequently, QoL-AGHDA scores in the English and Welsh KIMS patients were transformed into QoL-AGHDA utility, and those were compared to utilities calculated in the respective general population. The aim of this study was to evaluate the effects of $\mathrm{GH}$,

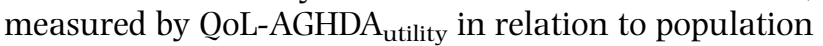




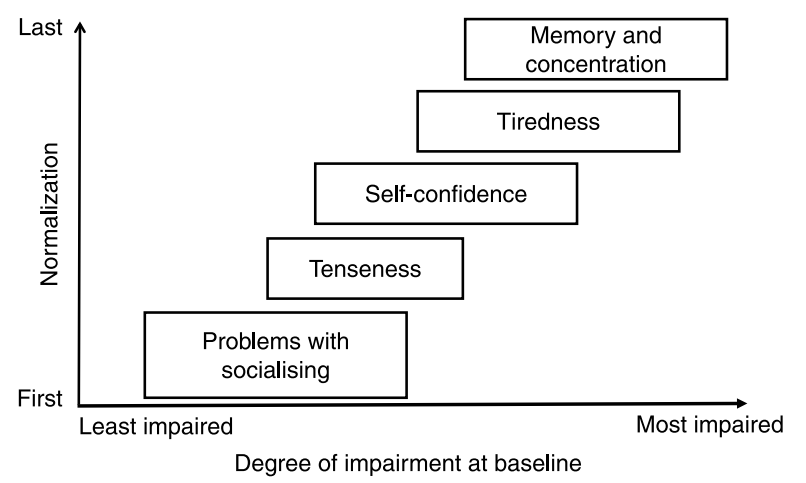

Figure 7 Dimensions by degree of impairment and order of improvement towards the population values. (KoltowskaHäggström et al. European Journal of Endocrinology 2006155 109-119. Reproduced with kind permission of the European Society of Endocrinology.

values and examine potential specificity in different

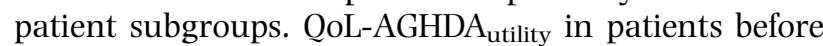
$\mathrm{GH}$ treatment differed from the population values $(0.67$, S.D. 0.174 vs 0.85 , S.D. $0.038 P<0.0001)$ constituting a mean deficit of -0.19 (s.D. 0.168). There was a

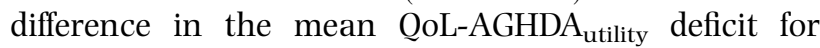
men -0.16 (s.D. 0.170) and women -0.21 (s.D. $0.162 ; P<0.001)$. The main improvement occurred during the first year of treatment; however, the patients' utilities remained impaired during subsequent followup, different $(P<0.001)$ from those reported by the general population. Despite an observed impact of age, primary aetiology, disease onset and co-morbidities on QoL-AGHDA $_{\text {utility, }}$ all patients showed similar beneficial response to treatment. The study concluded that utility derived directly from the QoL-AGHDA efficiently monitors treatment effects in patients with GHD and can be used as treatment outcome in health economic evaluations.

\section{Source of data: strengths and limitations of open observational studies}

The presented summary of the KIMS studies on QoL in adult GHD should be viewed in the light of strengths and limitations inherent in the nature of large, open observational surveys. As the principle of such surveys is to reflect routine clinical practice by collecting clinical information with no restrictions on the number of patients enrolled, the duration of follow-up or setting strict study inclusion criteria $(71,72)$, their main strengths lie in the large number of patients and corresponding extensive, longitudinal, long-term observations, as well as documentation of everyday clinical practice based in 'real life'. The abundance of data provides, as shown in our paper, possibilities to study specific patient subgroups, also in country-specific settings and to analyse long-term follow-up of certain clinical parameters.
There are, however, certain limitations, which should be borne in mind while conducting studies within an observational database survey. Such limitations can be categorized as related to the patient cohort, e.g. selection bias, comparability of patient subsets and problems with pooling data, completeness of data and unequal duration of follow-up as well as limited availability of comparators. The detailed discussion on strengths and limitations of observational surveys/databases is included in the introductory article by Wilton in this issue of the European Journal of Endocrinology (73).

\section{Final remarks}

Impaired QoL with its clinical, psychological and health economic consequences is an important clinical feature of GHD in adult patients and assessment of the QoL dimensions particularly related to energy and vitality, is of value in monitoring treatment effects (74). In this article, we provide a critical review of the evidence on QoL in adult GHD derived from the KIMS database and show ways in which it complements information based on other types of studies. We conclude that the wide spectrum of analyses performed on the KIMS data allows for practical application of the results not only to research and clinical practice but also to health policy and global medical decision making.

\section{Declaration of interest}

Maria Kołtowska-Häggström and Anders F Mattsson are permanently employed by Pfizer Health AB. Stephen M Shalet received speaker fees from Pfizer and Eli Lilly. KIMS ${ }^{\circledR}$ is supported by Pfizer Inc. This paper forms part of a European Journal of Endocrinology supplement, supported by Pfizer Inc.

\section{Acknowledgements}

The authors thank the KIMS investigators worldwide who provided the data on their patients and Mr Björn Westberg (KIMS Medical Outcomes, Pfizer Endocrine Care, Sollentuna, Sweden), Mrs Malin Dannemann and Mr Micael Edlund (EO Grafiska, Stockholm, Sweden) for preparing the figures. Björn Westberg is employed by Pfizer Health AB. The work of Mrs Dannemann and Mr Edlund was sponsored by Pfizer Health AB.

\section{References}

1 O'Connor R In Measuring Quality of Life in Health, pp 1-22. Churchill Livingstone: Elsevier Ltd, 2004.

2 Torrance GW. Measurement of health state utilities for economic appraisal. Journal of Health Economics 19865 1-30.

3 Carroll PV, Christ ER, and the members of Growth Hormone Research Society Scientific Committee: Bengtsson B- $\AA$, Carlsson L, Christiansen JS, Clemmons D, Hintz R, Ho K, Laron Z, Sizonenko P, Sönksen PH, Tanaka T \& Thorner M. Growth hormone deficiency in adulthood and the effects of growth hormone replacement: a review. Journal of Clinical Endocrinology and Metabolism $1998 \mathbf{8 3}$ 382-395. 
4 Björk S, Jonsson B, Westphal O \& Levin JE. Quality of life of adults with growth hormone deficiency: a controlled study. Acta Paediatrica Scandinavica 1989356 55-59.

5 McGauley GA, Cuneo R, Salomon F \& Sönksen PH. Psychological well-being before and after growth hormone treatment in adults with growth hormone deficiency. Hormone Research 199033 52-54.

6 Rosén T, Wirén L, Wilhelmsen L, Wiklund I \& Bengtsson B-Å. Decreased psychological well-being in adult patients with growth hormone deficiency. Clinical Endocrinology 199440 111-116.

7 Wallymahmed ME, Foy P, Shaw D, Hutcheon R, Edwards EHT \& MacFarlane IA. Quality of life, body composition and muscle strength in adult growth hormone deficiency: the influence of growth hormone replacement therapy up to 3 years. Clinical Endocrinology 199747 439-446.

8 Wirén L, Bengtsson B-Å \& Johannsson G. Beneficial effects of long-term GH replacement therapy on quality of life in adults with GH deficiency. Clinical Endocrinology $1998 \mathbf{4 8} 613-620$.

9 Holmes SJ, McKenna SP, Doward LD, Hunt SM \& Shalet SM. Development of a questionnaire to assess the quality of life of adults with GHD. Endocrinology and Metabolism 1995 2 63-69.

10 Hunt SM, McKenna SP \& Doward LC. Preliminary report on the development of a disease-specific instrument for assessing quality of life of adults with growth hormone deficiency. Acta Endocrinologica $1993 \mathbf{1 2 8} 37-40$.

11 Deijen JB, de Boer H, Blok GJ \& van der Veen EA. Cognitive impairments and mood disturbances in growth hormone deficient men. Psychoneuroendocrinology 199621 313-322.

12 van Dam PS, de Winter CF, de Vries R, van der Grond J, Drent ML, Lijffijt M, Kenemans JL, Aleman A, de Haan EHF \& Koppeschaar HPF. Childhood-onset growth hormone deficiency, cognitive function and brain $\mathrm{N}$-acetylaspartate. Psychoneuroendocrinology $200530357-363$.

13 Bülow B, Hagmar L, Ørbæk P, Österberg K \& Erfurth EM. High incidence of mental disorders, reduced mental well-being and cognitive function in hypopituitary women with $\mathrm{GH}$ deficiency treated for pituitary disease. Clinical Endocrinology $2002 \mathbf{5 6}$ 183-193.

14 Arwert LI, Deijen JB, Witlox J \& Drent ML. The influence of growth hormone $(\mathrm{GH})$ substitution on patient-reported outcomes and cognitive functions in GH-deficient patients: a meta-analysis. Growth Hormone and IGF Research 2005 15 47-54.

15 Woodhouse LC, Mukherjee A, Shalet SM \& Ezzat S. The influence of growth hormone status on physical impairments, functional limitations, and health-related quality of life in adults. Endocrine Reviews 200627 287-317.

16 Mårdh G, Lundin K, Borg G, Jonsson B \& Lindeberg A on behalf of the investigators. Growth hormone replacement therapy in adult hypopituitary patients with growth hormone deficiency: combined data from 12 European placebo-controlled clinical trials. Endocrinology and Metabolism 19941 (Supplement A) 43-49.

17 Attanasio AF, Lamberts SWJ, Matranga AMC, Birkett MA, Bates PC, Valk NK, Hilsted J, Bengtsson BA \& Strasburger CJ the Adult Growth Hormone Deficiency Study Group. Adult growth hormone (GH)-deficient patients demonstrate heterogeneity between childhood onset and adult onset before and during human GH treatment. Journal of Clinical Endocrinology and Metabolism $1997 \mathbf{8 2} 82-88$.

18 Verhelst J, Abs R, Vandeweghe M, Mockel J, Legros JJ, Copinschi G, Mahler C, Velkeniers B, Vanhaelst L, van Aelst A, de Rijdt D, Stevenaert A \& Beckers A. Two years of replacement therapy in adults with growth hormone deficiency. Clinical Endocrinology $199747485-494$.

19 Chihara K, Kato Y, Kohno H, Takano K, Tanaka T, Teramoto A \& Shimatsu A. Efficacy and safety of GH in the treatment of adult Japanese patients with GHD: a randomized, placebo-controlled study. Growth Hormone and IGF Research 200616 132-142.

20 Deijen JB, de Boer H, Blok GJ \& van der Veen EA. Cognitive changes during growth hormone replacement in adult men. Psychoneuroendocrinology 199823 41-45.
21 Carroll PV, Littlewood R, Weissberger AJ, Bogalho P, McGauley G, Sönksen PH \& Russell-Jones DL. The effects of two doses of replacement growth hormone on the biochemical, body composition and psychological profiles of growth hormone deficient adults. European Journal of Endocrinology 1997137 146-153.

22 Burman P, Broman JE, Hetta J, Wiklund I, Erfurth EM, Hagg E \& Karlsson FA. Quality of life in adults with growth hormone $(\mathrm{GH})$ deficiency: response to treatment with recombinant human $\mathrm{GH}$ in a placebo-controlled 21-month trial. Journal of Clinical Endocrinology and Metabolism $1995803585-3590$.

23 Cuneo RC, Judd S, Wallace JD, Perry-Keene D, Burger H, Lim-Tio S, Strauss B, Stockigt J, Topliss D, Alford F, Hew L, Bode H, Conway A, Handelsman D, Dunn S, Boyages S, Cheung NW \& Hurley D. The Australian multicenter trial of growth hormone (GH) treatment in GH-deficient adults. Journal of Clinical Endocrinology and Metabolism $1998 \mathbf{8 3} 107-116$.

24 Beshyah SA, Freemantle C, Shahi M, Anyaoku V, Merson S, Lynch S, Skinner E, Sharp P, Foale R \& Johnston DG. Replacement treatment with biosynthetic human growth hormone in growth hormone-deficient hypopituitary adults. Clinical Endocrinology 199542 73-84.

25 Baum HBA, Katznelson L, Sherman JC, Biller BMK, Hayden DL, Schoenfeld DA, Cannistraro KE \& Klibanski A. Effects of physiological growth hormone $(\mathrm{GH})$ therapy on cognition and quality of life in patients with adult-onset GH deficiency. Journal of Clinical Endocrinology and Metabolism 199883 3184-3189.

26 Sathiavageeswaran M, Burman P, Lawrence D, Harris AG, Falleti MG, Maruff P \& Wass J. Effects of GH on cognitive function in elderly patients with adult-onset GH deficiency: a placebocontrolled 12-month study. European Journal of Endocrinology 2007156 439-447.

27 Rosilio M, Blum WF, Edwards DJ, Berthezene F, Shavrikova EP, Valle D, Lamberts SWJ, Erfurth EM, Webb SM, Ross RJ, Chihara K, Henrich G, Herschbach P \& Attanasio AF. Long-term improvement of quality of life during growth hormone (GH) replacement therapy in adults with GH deficiency, as measured by questions on Life Satisfaction-Hypopituitarism (QLS-H). Journal of Clinical Endocrinology and Metabolism 200489 1684-1693.

28 Ranke MB. The role of large databases in outcomes research. In GH Replacement in Adults - The First 5 Years in KIMS, pp 1-5. Eds B $\AA$ Bengtsson \& JP Monson, Oxford: Oxford PharmaGenesis Ltd, 2000.

29 Gutiérrez LP, Kołtowska-Häggström M, Jönsson PJ, Mattsson AF, Svensson D, Westberg B \& Luger A. Registries as a tool in evidencebased medicine: example of KIMS (Pfizer International Metabolic Database). Pharmacoepidemiology and Drug Safety 200817 90-102.

30 McKenna SP, Doward LC, Alonso J, Kohlmann T, Niero M, Prieto L \& Wirén L. The QoL-AGHDA: an instrument for the assessment of quality of life in adults with growth hormone deficiency. Quality of Life Research 19998 373-383.

31 Dupuy HJ. The psychological general well-being (PGWB) index. In Assessment of Quality of Life in Clinical Trials of Cardiovascular Therapies, pp 170-183. Eds NK Wenger, ME Mattson, CF Furberg \& J Elinson, New York: Le Jacq Publishing, 1984.

32 Hunt SM, McKenna SP, McEwen J, Williams J \& Papp E. The Nottingham health profile: subjective health status and medical consultations. Social Science and Medicine 198115 221-229.

33 EuroQoL Group. EuroQoL - a new facility for the measurement of health-related quality of life. Health Policy 199016 19-208.

34 Saller B, Mattsson AF, Kann PH, Koppeschaar HP, Svensson J, Pompen M \& Kołtowska-Häggström M. Healthcare utilization, quality of life and patient-reported outcomes during two years of growth hormone $(\mathrm{GH})$ replacement therapy in GH-deficient adults - comparison between Sweden, The Netherlands and Germany. European Journal of Endocrinology 2006154 843-850.

35 Hunt SM \& McKenna SP. The QLDS: a scale for the measurement of quality of life in depression. Health Policy 199222 307-319.

36 Koltowska-Häggström M, Hennessy S, Mattsson AF, Monson JP \& Kind P. Quality of life assessment of growth hormone deficiency in adults (QoL-AGHDA): comparison of normative reference data for 
the general population of England and Wales with results for adult hypopituitary patients with growth hormone deficiency. Hormone Research $2005 \mathbf{6 4} 46-54$.

37 Koltowska-Häggström M, Mattsson AF, Monson JP, Kind P, Badia X, Casanueva FF, Busschbach J, Koppeschaar HPF \& Johannsson G. Does long-term growth hormone replacement therapy in hypopituitary adults with growth-hormone deficiency normalise quality of life? European Journal of Endocrinology 2006 155 109-119.

38 Koltowska-Häggström M, Kind P, Monson JP \& Jonsson B. Growth hormone replacement in hypopituitary adults with growth hormone deficiency evaluated by a utility-weighted quality of life index: a precursor to cost-utility analysis. Clinical Endocrinology 200868 122-129.

39 Badia X, Lucas A, Sanmarti A, Roset M \& Ulied A. One-year followup of quality of life in adults with untreated growth hormone deficiency. Clinical Endocrinology 199849 765-771.

40 Wirén L, Whalley D, McKenna SP \& Wilhelmsen L. Application of a disease-specific, quality-of-life measure (QoL-AGHDA) in growth hormone deficient adults and a random population sample in Sweden: validation of the measure by Rasch analysis. Clinical Endocrinology 200052 143-152.

41 Koltowska-Häggström $\mathrm{M}$, Jonsson $\mathrm{B}$, Isacson D \& Bingefors $\mathrm{K}$. Using EQ-5D to derive general population-based utilities for the quality of life-assessment of growth hormone deficiency in adults (QoL-AGHDA). Value in Health 200710 73-81.

42 McKenna SP \& Hunt S. The general well-being index: adapting and re-testing an American measure for use in the United Kingdom. British Journal of Medical Economics 19924 41-50.

43 Hernberg-Ståhl E, Luger A, Abs R, Bengtsson BÅ, FeldtRasmussen U, Wilton P, Westberg B \& Monson JP. Healthcare consumption decreases in parallel with improvements in quality of life during $\mathrm{GH}$ replacement in hypopituitary adults with $\mathrm{GH}$ deficiency. Journal of Clinical Endocrinology and Metabolism 2001 86 5277-5281.

44 Abs R, Bengtsson BÅ, Hernberg-Ståhl E, Monson JP, Tauber JP, Wilton P \& Wüster C. GH replacement in 1034 growth hormone deficient hypopituitary adults: demographic and clinical characteristics, dosing and safety. Clinical Endocrinology 199950 703-713.

45 Bengtsson B-Å, Abs R, Bennmarker H, Monson JP, FeldtRasmussen U, Hernberg-Ståhl E, Westberg B, Wilton $\mathrm{P}$ \& Wüster $\mathrm{C}$. The effects of treatment and the individual responsiveness to growth hormone $(\mathrm{GH})$ replacement therapy in 665 GH-deficient adults. Journal of Clinical Endocrinology and Metabolism 199954 3929-3936.

46 Monson JP, Abs R, Bengtsson B-Å, Bennmarker H, FeldtRasmussen U, Hernberg-Ståhl E, Thoren M, Westberg B, Wilton P \& Wüster C. Growth hormone deficiency and replacement in elderly hypopituitary adults. KIMS Study Group and the KIMS International Board. Pharmacia and Upjohn International Metabolic Database. Clinical Endocrinology 2000 53 281-289.

47 Svensson J, Mattsson A, Rosén T, Wirén L, Johansson G, Bengtsson B-Å \& Koltowska-Häggström M. Three-years of growth hormone $(\mathrm{GH})$ replacement therapy in GH-deficient adults: effects on quality of life, patient-reported outcomes and healthcare consumption. Growth Hormone and IGF Research 2004 4 207-215.

48 Moock J, Albrecht C, Friedrich N, Völzke H, Nauck M, KoltowskaHäggström M, Kohlmann T \& Wallaschofski H. Health-related quality of life and IGF-I in growth hormone deficient adult patients on growth hormone replacement therapy: analysis of the german KIMS data and the study of health in pomerania (SHIP). European Journal of Endocrinology 2009160 17-24.

49 Feldt-Rasmussen U, Abs R, Bengtsson BA, Bennmarker H, Bramnert M, Hernberg-Ståhl E, Monson JP, Westberg B, Wilton P \& Wüster C. Growth hormone deficiency and replacement in hypopituitary patients previously treated for acromegaly and Cushing's. European Journal of Endocrinology $200214667-74$
50 Kendall-Taylor P, Jönsson PJ, Abs R, Erfurth EM, KoltowskaHäggström M, Price DA \& Verhelst J. The clinical, metabolic, endocrine features and quality of life in adults with childhoodonset craniopharyngioma compared with adult-onset craniopharyngioma. European Journal of Endocrinology 2005152 557-567.

51 Verhelst J, Kendall-Taylor P, Erfurth EM, Price DA, Geffner M, Kołtowska-Häggström M, Jönsson PJ, Wilton P \& Abs R. Baseline characteristics and response to 2 years of growth hormone $(\mathrm{GH})$ replacement of hypopituitary patients with GH deficiency due to adult-onset craniopharyngioma in comparison with patients with non-functioning pituitary adenoma: data from KIMS (Pfizer International Database). Journal of Clinical Endocrinology and Metabolism $2005904636-4643$.

52 Höybye C, Jönsson P, Monson JP, Kołtowska-Häggström M, Hána V, Geffner M \& Abs R. Impact of the primary aetiology upon the clinical outcome of adults with childhood-onset growth hormone deficiency. European Journal of Endocrinology 2007157 589-596.

53 Monson JP \& Jönsson P. Aspects of growth hormone (GH) replacement in elderly patients with $\mathrm{GH}$ deficiency: data from KIMS. Hormone Research 200355 (Supplement 1) 112-120.

54 Abs R, Mattsson AF, Bengtsson B- $\AA$, Feldt-Rasmussen U, Goth MI, Koltowska-Haggstrom M, Monson JP, Verhelst J \& Wilton P. Isolated growth hormone $(\mathrm{GH})$ deficiency in adult patients: baseline clinical characteristics and responses to $\mathrm{GH}$ replacement in comparison with hypopituitary patients. A sub-analysis of the KIMS database. Growth Hormone and IGF Research 200515 349-359.

55 Siyambalapitiya S, Jonsson P, Koltowska-Haggstrom M, Gaillard R, Ho K \& Ross RJM. A cross-sectional analysis of testosterone therapies in hypopituitary men on stable pituitary hormone replacement. Clinical Endocrinology 2009 70 907-913.

56 Maiter D, Abs R, Johannsson G, Scanlon M, Jönsson PJ, Wilton P \& Koltowska-Häggström M. Baseline characteristics and response to growth hormone $(\mathrm{GH})$ replacement of hypopituitary patients previously irradiated for pituitary adenoma or craniopharyngioma: data from KIMS (Pfizer International Metabolic Database). European Journal of Endocrinology 2006155 253-260.

57 Keleştimur F, Jönsson P, Molvalilar S, Gomez JM, Auernhammer CJ, Colak R, Koltowska-Häggström M \& Góth MI. Sheehan's syndrome: baseline characteristics and effect of 2 years of growth hormone replacement therapy in 91 patients in KIMS Pfizer International Metabolic Database. European Journal of Endocrinology 2005152 581-587.

58 Casanueva FF, Leal A, Koltowska-Häggström M, Jönsson P \& Góth MI. Traumatic brain injury (TBI) as a relevant cause of GHD in adults: a KIMS-based study. Archives of Physical Medicine and Rehabilitation $200586463-468$.

59 Kreitschmann-Andermahr I, Poll EM, Reineke A, Gilsbach JM, Brabant G, Buchfelder M, Fassbender W, Faust M, Kann PH \& Wallaschofski H. Growth hormone deficient patients after traumatic brain injury - baseline characteristics and benefits after growth hormone replacement - an analysis of the German KIMS database. Growth Hormone and IGF Research $2008 \mathbf{1 8}$ $472-478$.

60 Abrams P, Boquete H, Fideleff H, Feldt-Rasmussen U, Jönsson PJ, Koltowska-Häggström M, Wilton P \& Abs R. Growth hormone replacement in hypopituitarism improves lipid profile and quality of life independently of changes in obesity variables. European Journal of Endocrinology 2008159 825-832.

61 Hürny C, Bernhard J, Gelber RD, Coates A, Castiglione M, Isley M, Dreher D, Peterson H, Goldhirsch A \& Senn HJ for the International Breast Cancer Study Group. Quality of life measures for patients receiving adjuvant therapy for breast cancer: an international trial. European Journal of Cancer 1992 28 118-124.

62 Inglehart R \& Rabier JR. Aspirations to adapt to situations but why are Belgians so much happier than the French? A cross-cultural 
analysis of the subjective quality of life. In Research on the Quality of Life, pp 1-56. Ed. FM Andrews. Ann Arbor Institute for Social Research, University of Michigan, 1986.

63 Blum WF, Shavrikova EP, Edwards DJ, Rosilio M, Hartman M, Marin F, Valle D, van der Lely AJ, Attanasio AF, Strasburger CJ, Henrich G \& Herschbach P. Decreased quality of life in adult patients with growth hormone deficiency compared with general populations using the new, validated, self-weighted questionnaire, questions on life satisfaction hypopituitarism module. Journal of Clinical Endocrinology and Metabolism 200388 4158-4167.

64 Hakkaart-van Roijen L, Beckers A, Stevenaert A \& Rutten FF. The burden of illness of hypopituitary adults with growth hormone deficiency. PharmacoEconomics 199814 395-403.

65 Sanmarti A, Lucas A, Hawkins F, Webb SM \& Ulied A On behalf of the collaborative ODA (Observational GH Deficiency in Adults). Group observational study in adult hypopituitary patients with untreated growth hormone deficiency (ODA study). European Journal of Endocrinology 1999141 481-489.

66 Ehrnborg C, Hakkaart-Van Roijen L, Jonsson B, Rutten FFH, Bengtsson BA \& Rosén T. Cost of illness in adult patients with hypopituitarism. PharmacoEconomics 200017 621-628.

67 Coast J. Is economic evaluation in touch with society's health values? BMJ 2004329 1233-1236.

68 Torrance GW. Utility approach to measuring health-related quality of life. Journal of Chronic Diseases 198740 593-600.
69 Torrance GW. Health status index models: a unified mathematical view management. Science 197622 990-1001.

70 Dixon S, McEwan P \& Currie CJ. Estimating the health utility of treatment in adults with growth hormone deficiency. Journal of Outcomes Research 20037 1-12.

71 Black N. What observational studies can offer decision makers. Hormone Research 199951 44-49.

72 Kahn MG. Clinical research databases and clinical decisison making in chronic diseases. Hormone Research 199951 50-57.

73 Wilton P. Foreword. European Journal of Endocrinology 2009161 S1-S2.

74 Ho KY and on behalf of the 2007. GH Deficiency Consensus Workshop Participants. Consensus Guidelines for the diagnosis and treatment of adults with GH deficiency II: a statement of the GH Research Society in association with the European Society for Paediatric Endocrinology, Lawson Wilkins Society, European Society of Endocrinology, Japan Endocrine Society, and Endocrine Society of Australia. European Journal of Endocrinology 2007157 695-700.

Received 5 July 2009

Accepted 6 July 2009 